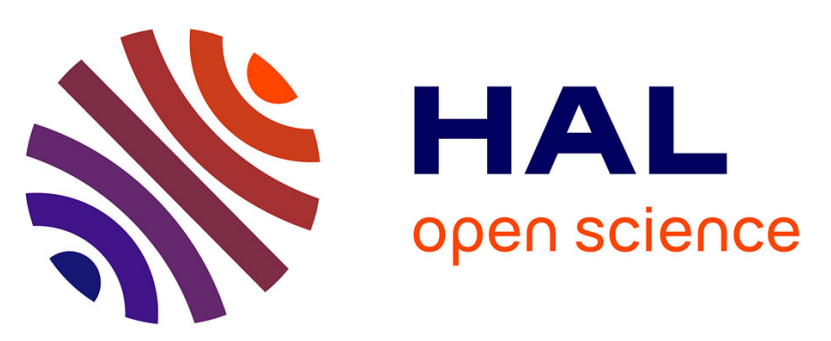

\title{
Photochemotherapy Induces a Faster Apoptosis of Alloreactive Activated T Cells Than of Nonalloreactive Resting T Cells in Graft Versus Host Disease
}

Dalil Hannani, Etienne Merlin, Françoise M. Gabert, David Laurin, Laurence Chaperot, Merlin Etienne, Francois Demeocq, Justyna Kanold, Recherche Transfusion, Hannani Dalil, et al.

\section{To cite this version:}

Dalil Hannani, Etienne Merlin, Françoise M. Gabert, David Laurin, Laurence Chaperot, et al.. Photochemotherapy Induces a Faster Apoptosis of Alloreactive Activated T Cells Than of Nonalloreactive Resting T Cells in Graft Versus Host Disease. Transplantation, 2010, 90 (11), pp.1232-1238. 10.1097/tp.0b013e3181fa4eb6 . hal-02047429

\section{HAL Id: hal-02047429 \\ https://hal.science/hal-02047429}

Submitted on 6 Jan 2021

HAL is a multi-disciplinary open access archive for the deposit and dissemination of scientific research documents, whether they are published or not. The documents may come from teaching and research institutions in France or abroad, or from public or private research centers.
L'archive ouverte pluridisciplinaire HAL, est destinée au dépôt et à la diffusion de documents scientifiques de niveau recherche, publiés ou non, émanant des établissements d'enseignement et de recherche français ou étrangers, des laboratoires publics ou privés. 


\section{Photochemotherapy Induces a Faster Apoptosis of Alloreactive Activated T Cells Than of Nonalloreactive Resting T Cells in Graft Versus Host Disease.}

Hannani Dalil 2,3, Gabert Françoise 2,3, Laurin David 2,3, Sall Mariam 3, Molens Jean-Paul 2,3, Hequet Olivier3, Chaperot Laurence 2,3, Plumas Joel 2,3

Inserm, U823, Immunobiologie et Immunotherapie des cancers, La Tronche, F-38706 France ; Univ Joseph Fourier, Grenoble, F-38041 France ;

EFS Rhône-Alpes, La Tronche, F38701 France

Running title: Effect of photochemotherapy on monocytes

Word Count:

Abstract : $200 \quad$ Text : 3631

Figures: $5 \quad$ References:27

Keywords : Extracorporeal Photochemotherapy, Monocytes, Apoptosis, Immunobiology

\section{Corresponding Author:}

Dr. Joel Plumas

Address : EFS RA, Laboratoire R\&D

29, avenue du maquis du Grésivaudan 38701 La Tronche France

E mail address: joel.plumas@efs.sante.fr

Tel : $+33(0) 4.76 .42 .43 .44 \quad$ Fax: $:+33(0) 4.76 .54 .69 .18$ 
Hannani et al. 
Hannani et al.

\section{Footnotes}

1 This work was supported by the Etablissement Français du Sang and Association Recherche et Transfusion.

${ }^{2}$ Inserm, U823, Immunobiologie et Immunotherapie des cancers, Grenoble, France ;

3 University of Grenoble - Joseph Fourier University, Grenoble, France ;

${ }^{4}$ Ełablissement Français du Sang Rhône-Alpes, Grenoble, France. 
Hannani et al.

\section{Abbreviations}

ECP: Extracorporeal Photochemotherapy

GvHD: Graft versus Host Disease

PUVA: Psoralen + UV A 
Hannani et al.

\section{Abstract:}

\section{Background:}

Extracorporeal photopheresis (ECP) is a powerful therapy currently used to treat various haematological disorders as in graft versus host disease (GVHD). Clinical data clearly demonstrate its efficacy and immunomodulation towards the pathogenic $T$ cells. However, ECP mechanism of action is still poorly understood.

Monocytes represent up to $30 \%$ of the total amount of treated cells and are known to play an important role in adaptive immunity. However, data from previous reports analyzing the effect of PUVA (psoralen and UV-A irradiation) on their functions are heterogeneous. In this study, we focused on the effect of PUVA on human monocytes functions in adaptive immunity.

\section{Design and Methods:}

Purified human monocytes were treated in vitro by PUVA. We measured their kinetic of apoptosis following the treatment. We also determine if their phenotype and functionalities were modified. Finally we assessed the functionalities of PUVA-treated monocytes-derived dendritic cells (DC).

\section{Results:}

PUVA treatment sentenced purified monocytes to die in six days and immediately altered their migratory capacities without impairing their ability of endocytosis. It also up-regulated co-stimulatory molecules and production of inflammatory cytokines upon activation and consequently stimulated allogeneic or autologous $T$ cells as efficiently as untreated monocytes. Moreover, PUVA-treated monocytes retained their ability to differentiate into fully functional DC that maturated and stimulated $T$ cells as well as normal DC.

\section{Conclusions:}

Our data demonstrate that monocytes undergo apoptosis and loose a part of their migratory capacity following ECP and the surviving cell functionalities are not impaired, suggesting that monocytes have a minor effect on ECP-mediated immunomodulation. 


\section{Introduction}

Extracorporeal photopheresis (ECP), a therapy initially developed for the treatment of cutaneous T-cell lymphoma $(C T C L)(1)$, is now currently employed for various hematological disorders involving pathogenic T-lymphocyte clones such as in GVHD(2). In latter, ECP proved very effective with impressive clinical results(3). Moreover, ECP is a safe and well-tolerated therapy. Briefly, ECP process consists of the withdrawal of a large amount of PBMC by apheresis (between 10 to 15 billions) followed by incubation with the photoactivable drug 8-MOP (8-methoxypsoralene) and UV-A irradiation (PUVA). Depending on the method used (on-line or off-line system), PUVA treated cells are reinfused back to the patient within 1 to 3 hours .

Patients usually receive 5 to 50 or even more procedures depending on their clinical response to the treatment. Although ECP procedure is rather simple but its mechanisms of action seem more complex and still remain enigmatic $(2,4)$. The direct effect of ECP on the treated cells is the formation of covalent linkage between DNA and 8MOP induced by the UV-A light(5). The treated cells, including pathogenic T cells, become unable to proliferate in vitro and undergo apoptosis after several hours(6-8). This apoptosis is well characterized, however, it cannot explain the efficacy of ECP because only a small proportion of pathogenic T cells is treated during the process. Indeed, in GVHD, like in CTCL, the pathogenic T cells are mainly located in periphery, so they are not directly affected by the 8-MOP/UV-A exposure. It has been proposed that in humans the immune system could downmodulate the pathogenic Tlymphocyte reactivity(4). In animal models, the injection of PUVA-treated cells to healthy animal has been shown to induce an immune response that impedes, after induction, the development of the pathology studied(8-11). However, in these studies the PUVA treated cells were taken from spleen, lymph nodes or in vitro 
Hannani et al.

cultured T-cells, whereas in human they are usually PBMC. Therefore, the immunomodulation and effectors identified in these studies could be different than those involved in human ECP. Among the treated cells, monocytes are a major group since they represent up to $30 \%$ of PBMC(12). It is well known that monocytes play an important role in adaptive immunity as they modulate immune responses and differentiate into dendritic cells(13). However, data from previous reports analyzing the direct effect of PUVA treatment on the functions of monocytes are heterogeneous(7, 14-17). In this study, we analyzed the kinetic of monocytes apoptosis after PUVA treatment and the changes in their functional characteristic involved in adaptive immunity. We also evaluated the effects of PUVA treatment on antigen-presenting function of monocytes and on their ability to differentiate into functional DC. 


\section{Material and Method}

\section{Medium and Reagents}

The cell culture medium used throughout these experiments was RPMI 1640 Glutamax (Invitrogen, Paisley, UK) supplemented with $1 \mathrm{mmol} / \mathrm{L}$ sodium pyruvate (Sigma-Aldrich, I'Isle d'Abeau, France), non-essential amino acids (Invitrogen), $20 \mathrm{ng} / \mathrm{ml}$ gentamicin (Invitrogen) and 10\% heat inactivated human AB serum (referred as complete medium).

Immunophenotyping was performed by using Fluorescein Isothiocyanate (FITC)-, Phycoerythrin (PE)-, PE-Cyanin5 or 7 (PC5 or PC7)- and Allophycocyanin (APC)conjugated and purified mouse monoclonal antibodies from Beckman Coulter (Marseille, France). IgG 2 isotypic control, IFNy and IL-4 antibodies were purchased from BD Biosciences (Pont de Claix, France).

Cells were stained with lgG1, lgG2a, CD1 1a, CD 14, CD40, CD54, CD58, CD80, CD83, CD86, CD209, HLA-I, HLA-II and HLA-DR markers. DioC6 (3,3-dihexyloxacarbocyanine iodide) and OVA-FITC were purchased from Invitrogen. Lucifer Yellow was purchased from Sigma-Aldrich. The 7-Aminoactinomycin D (7AAD) viability dye was purchased from Beckman Coulter. The 8-methoxypsoralen (8-MOP) was provided by our cell therapy unit. Flow cytometric analyses were performed using a 4 colors FACScalibur flow cytometer and the CellQuest-Pro software (BD Biosciences).

\section{Cell purification}

Blood samples were collected from three healthy volunteers who gave their written informed consent. The peripheral blood mononuclear cells (PBMC) were separated by density gradient on Iymphocyte separation medium (Eurobio, Les Ulis, France). Monocytes and T cells were purified according to the manufacturer instructions by 
Hannani et al.

using the human monocyte enrichment cocktail RosetteSep and from PBMC using the human T cells enrichment cocktail EasySep kit (Stem Cell Technologies Inc, Vancouver, Canada) respectively. Cells were cryopreserved in liquid nitrogen until use.

\section{Monocyte-derived dendritic cells (moDC) generation}

Purified monocytes were seeded at $0.5 \times 10^{6} \mathrm{cells} / \mathrm{ml}$ in a complete medium in the presence of 50U/ml of GM-CSF (Leucomax, Shering Plough,France) and $10 \mathrm{ng} / \mathrm{ml}$ of IL-4 (Tebu, Le Perray-en-Yvelines, France) as previously described(18). Both cytokines were added at day 0 and additional IL-4 at day 3 . After 6 days immature moDCs were harvested and verified as CD14-CD209+ by flow cytometry.

\section{Experimental Psoralen/UV-A treatment (PUVA)}

Purified monocytes were seeded at $1 \times 10^{6} \mathrm{cells} / \mathrm{ml}$ in a complete medium. Cells were incubated for $15 \mathrm{~min}$ at $37^{\circ} \mathrm{C}$ with $200 \mathrm{ng} / \mathrm{ml}$ of $8-\mathrm{MOP}$ in the dark and were exposed to $2 \mathrm{~J} / \mathrm{cm}^{2} 365 \mathrm{~nm}$ wavelength UV-A radiation (Bio Sun, Vilbert-Lourmat). After PUVA treatment, cells were washed in a complete medium and then cultured in the same medium at $37^{\circ} \mathrm{C}$ in $5 \%$ atmosphere $\mathrm{CO}_{2}$.

\section{Cell Viability}

Apoptotic cells were quantified by DioC6/7AAD staining as described previously (19). DioC6 was used to monitor mitochondrial transmembrane potential disruption.

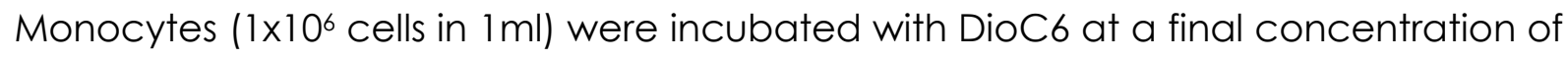
$1 \mathrm{nM}$ for $15 \mathrm{~min}$ at $37^{\circ} \mathrm{C}$. Cells were washed in PBS and then analyzed by flow cytometry.

Percentage of specific apoptosis was calculated by taking into account of the number and the viability of cells as follows: 
Hannani et al.

$\left[(\mathrm{nb} \text { cells }) \times\left(\% \text { DioC6 } 6^{+} \text {cells }\right)\right]_{\text {control }}-\left[(\mathrm{nb} \text { cells }) \times\left(\% \text { DioC6 }{ }^{+} \text {cells }\right)\right]_{\text {PUVA }}$

$\left[(\mathrm{nb} \text { of cells }) \times\left(\% \text { DioC6 }{ }^{+} \text {cells }\right)\right]_{\text {control }}$

\section{Endocytosis}

Endocytosis of monocytes was assayed by Lucifer Yellow and Ovalbumine-FITC after PUVA treatment. $2 \times 10^{5}$ monocytes in $200 \mu \mathrm{l}$ of RPMI with $10 \%$ Fetal Calf Serum (FCS) medium were incubated with $1 \mathrm{mg} / \mathrm{ml}$ of Lucifer yellow or $0.1 \mathrm{mg} / \mathrm{ml}$ of FITCconjugated ovalbumine in polypropylene tubes (BD Bioscience) for 3 hours at $37^{\circ} \mathrm{C}$ in $5 \% \mathrm{CO}_{2}$ to allow endocytosis. Negative control was performed at $4^{\circ} \mathrm{C}$. For ovalbuminmacropinocytosis -negative control, cells were incubated at $37^{\circ} \mathrm{C}$ in the presence of $10 \mu \mathrm{g} / \mathrm{ml}$ of Cytochalasin D (Sigma-Aldrich). After 3 hours, cells were centrifuged twice in HBSS with $2 \% \mathrm{FCS}$ and then the pellet was incubated with CD1 $1 \mathrm{~b}$ antibody. Phagocytic cells were determined as CD11b-FITC/Lucifer Yellow (FL-2) or OvaFITC/CD 11 b-PE double positive cells by flow cytometry.

\section{Cells activation and Cytokine production}

Monocytes $\left(1 \times 10^{6}\right)$ were cultured in $1 \mathrm{ml}$ of complete medium and activated with $1 \mathrm{\mu g} / \mathrm{ml}$ LPS (Sigma-Aldrich) for 24hours. Immature moDCs were produced as described above. At day 6 , they were activated with $1 \mu \mathrm{g} / \mathrm{ml}$ LPS and $100 \mathrm{ng} / \mathrm{ml}$ IFNY (Peprotech Neuilly sur Seine, France) for 48 hours.

Culture supernatants from activated monocytes and moDCs were collected after 24 and 48 hours respectively. The contents were analyzed for IL-1, IL-6, IL-8, IL-10, IL-12 p70 and TNFa by Cytokine Bead Array (CBA) inflammation kit (BD Biosciences) according to the manufacturer's recommendations with FACScan (BD Bioscience). Data were analyzed with CBA software (BD Biosciences). 
Hannani et al.

\section{Transwells chemotaxis assay}

Migration assays were carried out by using transwells $16.5 \mathrm{~mm}$ diameter, COSTAR, Cambridge, MA, USA) with $5.10^{5}$ cells/well. Control or treated PBMCs were washed, preincubated for $1 \mathrm{~h}$ at $37^{\circ} \mathrm{C}$ in RPMI with FCS $2 \%$ and then placed for $2 \mathrm{~h}$ in $5 \mu \mathrm{m}$ pore size inserts at $37^{\circ} \mathrm{C}$. The migrating monocytes were harvested and immunostained with CDI4-FITC. The results were shown as the percentage of monocytes which have migrated relative to the input number of monocytes. The chemokines used were MCP-1/CCL2 (CCR2), MIP-1B/CCL4 (CCR5), RANTES/CCL5 (CCR1) and SDF-1a/CXCL12 (CXCR4), at 100,50, 50 and $100 \mathrm{ng} / \mathrm{mL}$ respectively (R\&D systems, MN, USA).

\section{Antigen specific $T$ cell amplication}

Autologous monocytes $\left(1 \times 10^{6} / \mathrm{ml}\right)$ were pulsed with $10 \mu \mathrm{M}$ of the influenza M1 peptide (GILGFVFTL; HLA-A2 restricted) for 3 h at $37^{\circ} \mathrm{C}$ in RPMI. Then $5 \mathrm{x} \square 10^{4}$ of control or treated Flu-monocytes were co- cultured with $1 \times 10^{5} \mathrm{~T}$ cells for 7 days. PE - FluM1/HLA-A2 tetramers (Beckman Coulter, France) were used for the staining of the M1 specific CD3+CD8+ T cells according to the manufacturer's recommendations.

\section{Mixed lymphocyte reaction}

Responding T lymphocytes and stimulating monocytes were purified from PBMC of two healthy volunteers. Unidirectional MLR were conducted in quadruplicate of 96well flat-bottom plates (BD Biosciences) by mixing $5 \times 10^{4}$ responding purified CD3+ $T$ cells and $5 \times 10^{3}$ to $5 \times \square 10^{4}$ monocytes or moDC +/- PUVA (ratio responding/stimulator cells from $1 / 1$ to $1 / 0.1$ ) in a final volume of $200 \mu l(20)$. After five days, $\left[{ }^{3} \mathrm{H}\right]$ thymidine was added to each well and cell were harvested after $18 \mathrm{~h}$ later (Cell harvester : Inotech $\mathrm{IH} 280$ Berthold) [ $\left.{ }^{3} \mathrm{H}\right]$ thymidine incorporation was measured by a liquid scintillatrion counter, TopCount NXT (Perkin Elmer). 
Hannani et al.

\section{T cell polarization}

A mixed lymphocyte reaction was performed as described above. After 6-day culture, cells were harvested and T cells were restimulated with $0.5 \mathrm{ng} / \mathrm{ml}$ of PMA and $5 \mathrm{ng} / \mathrm{ml}$ of lonomycine (Sigma-Aldrich) for 6 hours. The secretion pathway was inhibited by using Monensine after 1 hour. At the end of the culture, cells were permeabilized by cytofix/cytoperm Kit (BD Bioscience) allowing the intracellular staining of IFNY and IL-4 (BD Bioscience). Analysis was performed by using a FACSCanto II cytometer (BD Bioscience).

\section{Statistical analysis}

The unpaired student's T-test or two-way ANOVA were used to determine if the differences observed between control and treated conditions were significant or non-significant. A value of $p<0.05$ was considered significant. 
Hannani et al.

\section{Results}

\section{Monocytes undergo apoptosis after exposure to PUVA}

First, we analyzed the kinetic of PUVA induced apoptosis, a direct effect of the treatment due to the formation of photo adducts(5). In this study we used DioC6 instead of the annexin- $V$ staining method(19) because the numerous platelets sticked on monocytes were highly bound to annexin- $V$ leading to a non specific labelling $(21,22)$. We cultured PUVA-treated monocytes for 6 days in the presence or absence of GM-CSF used here as a monocyte-survival factor. At day 0, more than $90 \%$ of monocytes were alive. Six days after PUVA treatment in presence of GM CSF about $80 \%$ of them were dead (Figure 1A). The observation of PUVA-monocytes after May-Grünwald-Giemsa staining clearly showed an apoptotic features (cell shrinkage, apoptotic bodies, nuclear condensation) as compared to untreated monocytes. Moreover, since monocytes have the ability to engulf cell debris or apoptotic bodies, we have also taken into account the absolute number of viable cells during the culture to calculate the percentage of specific apoptosis. The results presented in figure 1B showed that specific apoptosis was continuously increasing in the days following the treatment. One day after treatment, the specific apoptosis was low (around 20\%) whereas at day 6 it reached up to $80 \%$. The presence of GMCSF did not change this kinetic suggesting that the sensitivity of monocytes to cell death was not modified by survival factors. Apoptosis induced by PUVA in monocytes has a slow kinetic and thus surviving treated cells may still be functional until day 6. 
Hannani et al.

\section{The main functions of monocytes are not altered by the PUVA treatment except their migratory capacities}

We then analyzed the effect of PUVA treatment on the capacity of monocytes to perform endocytosis. Capture of Lucifer Yellow (LY) was used as a model of pinocytosis and FITC-ovalbumine (FITC-OVA) as a model of macropinocytosis. After 3-hours incubation at $37^{\circ} \mathrm{C}$, more than $90 \%$ of the monocytes efficiently engulfed LY and FITC-OVA (Figure 2). The PUVA treatment neither affected the percentage of positive cells nor the intensity of labeling, meaning that the endocytic ability of monocytes was not altered.

As monocytes died slowly following PUVA treatment, it can be assumed that once they are injected back to the patient these cells could still be able to migrate in periphery or in the lymphoid organs and/or to stimulate T-cells. So, we evaluated the expression of molecules involved in these processes on control or PUVA - monocytes. Moreover, for an optimal T-lymphocytes stimulation, monocytes are required to present peptide associated to HLA molecules and to provide costimulation signal via molecules such as CD40 and CD86 in the immune synapse reinforced by adhesion molecules such as CD11a, CD54 and CD58. These molecules were constitutively expressed on monocytes at various levels (data not shown). Twenty-four hours following PUVA treatment, we did not observe any significant change of their expression in comparison to untreated cells (figure $3 \mathrm{~A}$ et $3 \mathrm{~B}$ ). Also, the main chemokine receptors expressed by monocytes were not modified by the treatment (figure 3C). Interestingly, despite an absence of a differential chemokine receptors expression, PUVA treatment significantly $(\mathrm{p}<0.01)$ impaired the monocytes migration towards CCL2 and CCL4 but not to CCL5 and CXCL12 (Figure 3D). These data suggest that reinfused treated monocytes have lost a part of their capacities to patrol in the body. 


\section{Hannani et al.}

We next analyzed the production of inflammatory or inhibitory cytokines by monocytes known to modify the immune response like IL-1b, TNF- $\square$ and IL-10. Monocytes were treated or not by PUVA and then activated or not by LPS for $24 \mathrm{~h}$ (figure 4A). Without activation, there was no cytokine production. The production of these cytokines after activation with LPS was affected neither positively nor negatively by the PUVA treatment. This suggests that PUVA does not modify the ability of monocytes to secrete cytokines in response to an infection or others stimulatory signals.

The APC function of the cells can be tested by performing a mixed lymphocyte reaction(18). Indeed, this assay reflects the global stimulatory capacities of APC taking into account the expression of molecules involved in the immunological synapse (HLA, costimulatory, adhesion molecules) and the cytokines released. As presented in figure 4B, after 6-day culture, the T-cell proliferation increased according to the number of allogeneic monocytes added in the culture. A similar Tcells proliferation was observed when PUVA-treated monocytes were used as APC. Moreover, the T cell polarization induced by either control or PUVA - monocytes was similar in both conditions (figure 4C). So, it appears that PUVA does not affect the allogeneic stimulatory potential of monocytes.

We next analyzed in autologous setting the impact of PUVA on the capacity of monocytes to induce antigen specific T-cells. Influenza Ml peptide pulsed monocytes were used to stimulate autologous T cells (Figure 4D). Following 7 day culture, the frequency of Flu-specific T cells reached to up to $15 \%$ in control condition and was not affected in the treated one. 
Hannani et al.

All together, these data indicate that immediately after PUVA the allogeneic and antigen-specific stimulation capacities of monocytes are not modified. By contrast, PUVA-treated monocytes seem to partially loose their migratory capacity.

\section{The PUVA treatment does not impair the differentiation of monocytes into functional dendritic cells}

Since dendritic cells are potent inducers of immune response and monocytes are one of their precursors, we asked if the PUVA treatment could alter or induce their differentiation into functional DC.

The differentiation of monocytes into DC was induced by 6-day culture with GM-CSF and IL-4. This differentiation can be easily evidenced by the concomitant decrease of CD14 and an increase of CD209 (DC-SIGN) expression. At day 0, monocytes were CD14+CD209- and after culture they become CD14-CD209+ DC (figure 5A). We then evaluated the impact of the PUVA treatment on this differentiation. As the PUVA treatment induce apoptosis in monocytes, we performed analysis only on the surviving cells for 6-day culture. Upon culture with IL-4 and GM-CSF, PUVA treatedmonocytes lost CD14 while they acquired CD209 with the same kinetic as control monocytes (figure 5B, upper panels). In addition, in the absence of cytokines, monocytes did not turn into DC as evidenced by the persistent expression of CDI4 and the low level of CD209 (figure 5B, lower panels), whatever were the conditions.

We then wondered if DC generated from treated-monocytes were functional by stimulating them with LPS in the presence of IFNY for $48 \mathrm{~h}$. We analyzed their activation by measuring the up-regulation of CD83, CD86 and CD40 and by production of cytokines. As presented in figure 5C, DC derived from treatedmonocytes up-regulated the expression of these activation markers to the same extent as non-treated monocytes. Regarding cytokine production, IL $1 \mathrm{~b}$ and IL-10 
Hannani et al.

were not detected whatever was the condition. However, it seems that the levels of IL-6, IL-12 and TNFa were slightly, but not significantly, lower in PUVA-monocytes derived DC condition (figure 5D). Moreover, when control and PUVA-moDC were used as stimulating cells for allogenic T cells, they both induce the same IL-4+/IFNY+ positive cells ratio (figure $5 \mathrm{E}$ ). These results suggest that the functions of PUVAmonocytes derived DC remain preserved. 
Hannani et al.

\section{Discussion}

ECP is a cell therapy commonly used for the treatment of diseases caused by pathogenic T cells like CTCL(1) or GVHD(2). However, its overall mechanism of action remains unclear. Several studies demonstrate the clinical beneficial effects of ECP, however the immune pathway leading to this ECP-mediated immunomodulation remains to be elucidated.

The ECP treatment has been shown to induce T-cell apoptosis $(7,23)$. Regarding monocytes, previous reports have presented heterogeneous data about the sensitivity of these cells to apoptosis(7, 14-17). We first analyzed the kinetic of monocytes apoptosis after the treatment. We also calculated the specific apoptosis by taking into account the absolute number of cells and their viability accessed with DioC6. This method appears to be more appropriate than the others because the phagocytic activity of monocytes by removing dead cells could alter the results leading to underestimate apoptosis. Moreover, the detection of apoptosis by the commonly used annexin- $V$ marker is unsuitable in this case because it binds to the numerous platelets(22) sticked onto monocytes membranes. We show that it takes 6 days for monocytes to undergo apoptosis whereas it takes only 3 days for T cells (/7, 23), unpublished results). So, following PUVA treatment monocytes apoptosis was slow compared to T cell apoptosis. This enhanced resistance of monocytes could be explained by the fact that, contrary to T cells, monocytes do not proliferate and hence could be less sensitive to apoptosis induced by PUVA(5). Interestingly, GM-CSF did not protect the cells from apoptosis, suggesting that the apoptotic process is definitely engaged following the treatment. 


\section{Hannani et al.}

We next analyzed whether the PUVA treatment could alter the main functions of monocytes in adaptive immunity. We evaluated monocytes properties just after the treatment as soon as possible because of the ongoing apoptosis and the treated cells are rapidly infused back to the patient during the therapeutic process. We observed that the treatment did not change the expression of specific homing receptors on monocytes but inhibit their migratory capacities toward CCL2 and CCL4 suggesting that they could not patrol in the body after reinfusion avoiding monocytes to play their role. Concerning the influence of the PUVA treatment on cytokine secretion, in contrast to other study(24), we did not detect any increase in the spontaneous production of TNF-alpha. This discrepancy could be explained by the differences in purification process, indeed, purification by adhesion or positive selection is known to activate monocytes. To avoid this risk, we purified them by a negative magnetic selection. In addition, unlike to some report(16), the PUVA treatment did not lead to the secretion of inhibitory molecules by monocytes such as IL-10. The absence of global inhibitory effect mediated by the PUVA treated monocytes was evidenced by their ability to induce a consistent allogeneic proliferation of $\mathrm{T}$ cells even when the monocytes/T cell ratio was high. Conversely, when this ratio was low, no increase of T-cell proliferation was observed with treated compared to untreated monocytes, suggesting that the treatment did not upregulate the stimulatory activity of monocytes. Also, their antigen-specific $T$ cell amplification capacities were not modified. These observations are consistent with the fact that the expression of costimulatory and adhesion molecules, and the secretion of cytokines were not modified by the treatment. Moreover, the observation that the endocytic capacity of treated monocytes remained unchanged suggests that monocyte main function is not impaired by PUVA treatment at least early after the treatment. 
Hannani et al.

Monocytes are precursors of dendritic cells in vivo but the previous data showed that the effect of PUVA treatment on this differentiation was heterogeneous $(17,25,26)$. In vitro, monocytes can easily be turned into DC by 6-day culture in the presence of GM-CSF and IL-4. In these conditions, we have shown here that PUVA-treated monocytes differentiated into dendritic cells with the same kinetic as non-treated cells. Contrary to a previous report(25) but confirmed by a recent work(26), we found that in the absence of added cytokines there was no spontaneous DC differentiation. This could be explain by the absence of plastic interaction in our condition. Moreover, whether monocytes were treated or not, the generated dendritic cells were able to mature in the presence of LPS as evidenced by the upregulation of costimulatory molecules and cytokines production. Moreover, both control and PUVA-moDC were able to induce the T cell polarization with the same extent, suggesting that they were fully functional and ECP do not modify their immunomodulatory properties. So, our results suggest that the low fraction of monocytes that did not undergo apoptosis after 6-day following PUVA treatment were still able to differentiate into fully functional DC only in the presence of differentiating cytokines. These data are consistent with the anti-tumor response hypothesized by Edelson et al $(25,27,28)$.

The demonstration that the main functions of monocytes were not impaired suggests that they have not a direct effect on the ECP-mediated immunomodulation. Moreover, after reinfusion, our data suggest that they become enable to migrate toward inflammatory sites. We show that the monocytes which are in great number among the cells treated by PUVA are sentenced to die like T cells, DC and probably all other cells (29). This injection back to the patient of huge amount PUVA-treated 
Hannani et al.

cells may induce indirect effects on immune response. For instance, Craciun et al showed that the treated cells trigger the synthesis of immunosuppressive cytokines by non-treated mononuclear cells(30). This could be responsible for the early clinical efficacy of ECP. It is now necessary to further analyze the impact of the treated cells on the long term immunomodulatory effects induced by ECP. 
Hannani et al.

\section{Acknowledgments}

We would like to thank MJ. Richard, H.Egelhofer and the staff of Cell and Tissue therapy Unit of Saint-Ismier for providing us the psoralen molecule. We are also grateful to P. Drillat, F. Bernard, C. Morand, I. Michaud, C. Guitton and the staff of EFS Rhône-Alpes for blood sample collections. We also thank R.Muhamad for critical review of the manuscript.

\section{Authorship}

D.H performed most of the experiments with the help of JP.M and M.S for some of them. D.H, J.P, D.L and O.H analyzed data. D.H, J.P LC and F.G designed the work and wrote the manuscript. 


\section{References}

1. Miller JD, Kirkland EB, Domingo DS, et al. Review of extracorporeal photopheresis in early-stage (IA, IB, and IIA) cutaneous T-cell lymphoma. Photodermatol Photoimmunol Photomed 2007; 23 (5): 163.

2. Marshall SR. Technology insight: ECP for the treatment of GvHD--can we offer selective immune control without generalized immunosuppression? Nat Clin Pract Oncol 2006; 3 (6): 302.

3. Dall'Amico R, Murer L. Extracorporeal photochemotherapy: a new therapeutic approach for allograft rejection. Transfus Apheresis Sci 2002; 26 (3): 197.

4. Plumas J, Manches O, Chaperot L. Mechanisms of action of extracorporeal photochemotherapy in the control of GVHD: involvement of dendritic cells. Leukemia 2003; 17 (11): 2061.

5. Kanne D, Straub K, Rapoport H, Hearst JE. Psoralen-deoxyribonucleic acid photoreaction. Characterization of the monoaddition products from 8methoxypsoralen and 4,5'8-trimethylpsoralen. Biochemistry 1982; 21 (5): 861.

6. Jacob MC, Manches $O$, Drillat $P$, et al. Quality control for the validation of extracorporeal photopheresis process using the Vilbert-Lourmat UV-A irradiation's system. Transfus Apher Sci 2003; 28 (1): 63.

7. Yoo EK, Rook AH, Elenitsas R, Gasparro FP, Vowels BR. Apoptosis induction of ultraviolet light $A$ and photochemotherapy in cutaneous T-cell Lymphoma: relevance to mechanism of therapeutic action. J Invest Dermatol 1996; 107: 235.

8. Truitt RL, Johnson BD, Hanke C, Talib S, Hearst JE. Photochemical treatment with S59 psoralen and ultraviolet $A$ light to control the fate of naive or primed T lymphocytes in vivo after allogeneic bone marrow transplantation. J Immunol 1999; 163 (9): 5145.

9. Ullrich SE. Photoinactivation of T-cell function with psoralen and UVA radiation suppresses the induction of experimental murine graft-versus-host disease across major histocompatibility barriers. J Invest Dermatol 1991; 96: 303.

10. Perez MI, Berger CL, Yamane Y, John L, Laroche L, Edelson RL. Inhibition of antiskin allograft immunity induced by infusions with photoinactivated effector $T$ lymphocytes--the congenic model. Transplantation 1991; 51: 1283.

11. Maeda A, Schwarz A, Kernebeck K, et al. Intravenous infusion of syngeneic apoptotic cells by photopheresis induces antigen-specific regulatory T cells. $J$ Immunol 2005; 174 (10): 5968.

12. Garban F, Drillat P, Makowski C, et al. Extracorporeal chemophototherapy for the treatment of graft-versus-host disease: hematologic consequences of short-term, intensive courses. Haematologica 2005; 90 (8): 1096.

13. Randolph GJ, Jakubzick C, Qu C. Antigen presentation by monocytes and monocytederived cells. Curr Opin Immunol 2008; 20 (1): 52.

14. Legitimo A, Consolini R, Di Stefano R, Bencivelli W, Mosca F. Psoralen and UVA light: an in vitro investigation of multiple immunological mechanisms underlying the immunosuppression induction in allograft rejection. Blood Cells Mol Dis 2002; 29 (1): 24.

15. Tambur AR, Ortegel JW, Morales A, Klingemann H, Gebel HM, Tharp MD. Extracorporeal photopheresis induces lymphocyte but not monocyte apoptosis. Transplant Proc 2000; 32 (4): 747. 
Hannani et al.

16. Di Renzo M, Rubegni $\mathrm{P}$, Pasqui $\mathrm{AL}$, et al. Extracorporeal photopheresis affects interleukin (IL)-10 and IL-12 production by monocytes in patients with chronic graftversus-host disease. Br J Dermatol 2005; 153 (1): 59.

17. Rao V, Saunes M, Jorstad S, Moen T. In vitro experiments demonstrate that monocytes and dendritic cells are rendered apoptotic by extracorporeal photochemotherapy, but exhibit unaffected surviving and maturing capacity after 30 Gy gamma irradiation. Scand J Immunol 2008; 68 (6): 645.

18. Chaperot L, Chokri M, Jacob MC, et al. Differentiation of antigen-presenting cells (dendritic cells and macrophages) for therapeutic application in patients with lymphoma. Leukemia 2000; 14 (9): 1667.

19. Manches $\mathrm{O}$, Lui G, Chaperot L, et al. In vitro mechanisms of action of rituximab on primary non-Hodgkin lymphomas. Blood 2003; 101 (3): 949.

20. Plumas J, Chaperot L, Richard MJ, Molens JP, Bensa JC, Favrot MC. Mesenchymal stem cells induce apoptosis of activated T cells. Leukemia 2005; 19 (9): 1597.

21. Silverstein RL, Nachman RL. Thrombospondin binds to monocytes-macrophages and mediates platelet-monocyte adhesion. J Clin Invest 1987; 79 (3): 867.

22. Thiagarajan $P$, Tait JF. Binding of annexin V/placental anticoagulant protein $I$ to platelets. Evidence for phosphatidylserine exposure in the procoagulant response of activated platelets. J Biol Chem 1990; 265 (29): 17420.

23. Enomoto DN, Schellekens PT, Yong SL, ten Berge IJ, Mekkes JR, Bos JD. Extracorporeal photochemotherapy (photopheresis) induces apoptosis in lymphocytes: a possible mechanism of action of PUVA therapy. Photochem Photobiol 1997; 65: 177.

24. Vowels BR, Cassin M, Boufal MH, Walsh LJ, Rook AH. Extracorporeal photochemotherapy induces the production of tumor necrosis factor-alpha by monocytes: implications for the treatment of cutaneous T-cell lymphoma and systemic sclerosis. J Invest Dermatol 1992; 98: 686.

25. Berger CL, Xu AL, Hanlon D, et al. Induction of human tumor-loaded dendritic cells. Int J Cancer 2001; 91 (4): 438.

26. Legitimo A, Consolini R, Failli $A$, et al. In vitro treatment of monocytes with 8methoxypsolaren and ultraviolet $A$ light induces dendritic cells with a tolerogenic phenotype. Clin Exp Immunol 2007; 148 (3): 564.

27. Berger CL, Hanlon D, Kanada D, Girardi M, Edelson RL. Transimmunization, a novel approach for tumor immunotherapy. Transfus Apheresis Sci 2002; 26 (3): 205.

28. Edelson RL. Transimmunization: the science catches up to the clinical success. Transfus Apheresis Sci 2002; 26 (3): 177.

29. Holtick U, Marshall SR, Wang XN, Hilkens CM, Dickinson AM. Impact of psoralen/UVA-treatment on survival, activation, and immunostimulatory capacity of monocyte-derived dendritic cells. Transplantation 2008; 85 (5): 757.

30. Craciun LI, Stordeur P, Schandene L, et al. Increased production of interleukin-10 and interleukin-1 receptor antagonist after extracorporeal photochemotherapy in chronic graft-versus-host disease. Transplantation 2002; 74 (7): 995. 
Hannani et al.

\section{Figure Legends}

\section{Figure 1: PUVA treatment induces apoptosis in monocytes}

Treated (PUVA) or untreated (Control) monocytes cultured in the medium with or without GM-CSF for 6 days were labeled by DioC6. Dead cells are defined as DioC6 negative cells. (A) May-Grünwald-Giemsa staining and dot plots from GM-CSF condition are shown which are representative of 3 independent experiments. (B) The graphs represent the kinetic of monocytes apoptosis after PUVA treatment. FSC: Forward Scatter; SSC: Side Scatter

Figure 2: Endocytic capacity of monocytes is not impaired following PUVA treatment

Endocytosis assays were performed 24h after PUVA treatment in the presence of either Lucifer Yellow (left panel) or FITC-OVA (right panel) at $37^{\circ} \mathrm{C}$ for 3 hours (black histogram). Negative controls were performed at $4^{\circ} \mathrm{C}$ (empty histogram) or at $37^{\circ} \mathrm{C}$ in presence of $10 \mu \mathrm{g} / \mathrm{ml}$ of Cytochalasin D. One experiment histogram is a representative of 2 performed with 2 donors.

Figure 3: Chemokine receptors, $M H C$ molecules and activation and adhesion markers expression are not modified on monocytes by PUVA treatment but their migratory capacities are impaired

PUVA effects were determined on the expression of class I and II MHC molecules (A), on the activation and adhesion markers (B) and on the chemokine receptors (C) on purified monocytes. PUVA treated or untreated cells were cultured and then analyzed by flow cytometry. The migration capacities of treated monocytes were evaluated by transwell assay (D) Data represent the mean $+/$ - s.d. of 2 independent 
Hannani et al.

experiments performed with monocytes from 2 donors. MFI: Mean Fluorescence Intensity.

Figure 4: PUVA treatment does not modify either cytokine production under activation or allostimulation or antigen specific stimulatory capacities of monocytes.

(A) Cytokine production of PUVA-treated monocytes activated by LPS for $24 \mathrm{~h}$ was measured by CBA inflammation kit. Data represent the mean +/- s.d. of 3 independent experiments performed with 3 donors. (B) Allogeneic mixed lymphocyte reaction was performed by mixing increasing amount of irradiated monocytes and purified allogeneic T lymphocytes. T lymphocytes proliferation was measured by the incorporation of $\left[{ }^{3} \mathrm{H}\right]$ thymidine after 6 days of culture. Data represent the cpm (mean +/- s.d.) of 2 independent experiments performed with 2 donors. (C) T cell polarization after 6-day culture with control or PUVA allogenic monocytes. Data represent the mean +/- s.d. of 3 independent experiments performed with 3 donors. (D) Amplification of Flu-specific T cells following 7-day culture with Influenza M1 peptide pulsed control or PUVA-treated monocytes.

Figure 5: PUVA treatment neither impairs the differentiation of monocytes into potent DC in the presence of cytokines nor induces their spontaneous differentiation

PUVA treated and untreated monocytes were cultured with or without GM-CSF and IL-4 for 6 days. CD14 and CD209 are specific markers for monocytes and dendritic cells respectively. (A) Representative histograms of three independent experiments performed with 3 donors represent CD14 and CD209 histogram at day 0 and 6, (B) CD14 and CD209 membrane expression on monocytes at day 0, 1, 3 and 6. Data 
Hannani et al.

represent the percentage of positive cells (mean +/- s.d.) of 2 independent experiments performed with 2 donors. (C) Immature DCs were obtained from PUVA treated and untreated monocytes cultured with GM-CSF and IL-4 for 6 days. DCs were matured by activation with LPS and IFNy for $48 \mathrm{~h}$ and the expression of activation markers were then analyzed by flow cytometry. The percentages of positive cells are represented. (D) Supernatants from mature DC were collected and the measurements cytokines were performed by CBA inflammation kit. Data represent the percentages of positive cells (mean +/- s.d.) of 3 independent experiments performed with 3 donors. (E) T cell polarization after 6-day culture with PUVA treated and control allogenic monocytes derived DC. Data represent the mean $+/$ - s.d. of 3 independent experiments performed with 3 donors. 